\title{
Digitalization as one of the directions of sustainable development of the integrated logistics system of the enterprise
}

\author{
Zinaida Khmelnitskaya ${ }^{1}$, Maria Ivich $^{1,2}$, and Elena Bogdanova ${ }^{3, *}$ \\ ${ }^{1}$ Ural State University of Economics, 8 Marta St/Narodnaya Volya St, 62/45, 620144 Ekaterinburg, \\ Russia \\ ${ }^{2}$ LLC SVX Logistics, Kuybysheva St, 82A, 620100 Ekaterinburg \\ ${ }^{3}$ Ural State University of Railway Transport, Kolmogorova St, 66, 6200034 Ekaterinburg, Russia
}

\begin{abstract}
Because of the pandemic of the new coronavirus infection, the pace of digitalization and its impact on all sectors of the national economy have increased. The integrated logistics systems of the enterprises have also undergone significant changes. The article examines the main trends of recent times - digitalization and integration, which provide development potential, competitive advantages for the enterprises using the integrated logistics systems. The authors investigated the impact of the new coronavirus infection on the changes in the logistics systems of the enterprise; identified eight main directions of the changes, one of which has become the acceleration of the digitalization along the entire chain of the integrated logistics systems. Further, the authors identified six characteristic constituent elements of the digitalization as one of the directions of the sustainable development. They examined the interaction between the functionalities of the integrated logistics system and the characteristic components of the digitalization.
\end{abstract}

\section{Introduction}

Last year was very difficult and unpredictable in terms of the economic situation around the world. The situation with the pandemic of the new coronavirus infection has made adjustments in all areas of our planet life, including the economies of all countries in the world and the global and local markets of logistics services. Certain changes occurred in a number of directions, in particular: there were restrictions or delays in the transportation of goods between countries, supplies shortage, financial difficulties for logistics operators; because of this, the enterprises were forced to optimize their logistics systems taking into account the new reality $[1,2]$. Outsourcing, strategic partnership and integration have come to be seen as the most effective ways for interaction between partners. COVID-19 has brought significant changes to the logistics sector, which have affected the industry. With the globalization of the production, the international companies such as BMW, which operates globally with 31 production and assembly sites in 15 countries of the world and

\footnotetext{
*Corresponding author: esbogdanova@rambler.ru
} 
sales covering 140 countries, must build efficient supply chains that ensure a smooth production and distribution process. And in the pandemic, this task becomes difficult to achieve without changes in the integrated logistics systems of the corporations.

The authors highlighted a number of main trends in the logistics market that have appeared in 2020-21, including because of the pandemic of the new coronavirus infection:

1. Compliance with sanitary standards and quarantine measures, including when crossing borders by drivers, and observance of social distances in warehouses have led to delays and an increase in delivery times, the appearance of additional costs and an increase in the cost of freight;

2. In the conditions of the pandemic, the movements were restricted and closed; and shopping centers and non-food stores are still closed in European countries. This has contributed to the growth of e-commerce, the demand for online purchases and food delivery services have increased. After the opening of all the stores many people still prefer online shopping.

3. Because of the high volatility of rates for air and sea transport, volumes are being redistributed towards the land transport, especially on the Asia - Europe routes. The increase in auto delivery time due to the quarantine measures has increased the delivery times and a lack of transport, which have led to the increase of the demand for rail and container transportation.

4. Due to the optimization of the logistics activity, caused by the need to increase economic efficiency in the context of the crisis associated with the pandemic, they have begun to look for new methods of delivery and handling of goods. There has been a need to accumulate stocks to ensure the uninterrupted production. The enterprises have begun to transfer more actively the non-core activities to outsourcing, which carries not only saving finances, but also the time, as well as improving customer service, which gives a competitive advantage. In the context of the pandemic, outsourcing of the logistics processes has begun to gain significantly higher growth rates.

5. The pandemic has exposed the vulnerability of the complex logistics chains, as a result of which international corporations have begun to review their supply chains and diversify by attracting alternative partners within their countries. Thus, businesses around the world are rebuilding their integrated logistics systems with a focus on domestic and/or other alternative markets. And the global cost chains have been transformed.

6 . The influence of large financial and industrial groups has increased. They are actively acquiring services of their own logistics - for example, «Sbermarket», «Yandex.Delivery» and «Delivery Club». The financial and industrial groups have sufficient financial potential to create large-scale information systems and build effective integrated logistics systems on their basis. This certainly gives them a lot of advantages and makes them the market leaders.

7. There has been a particular increase in demand for «last mile» automation and digitalization. Initially, the automation in the integrated logistics systems, as a rule, was carried out from warehouse processes, the accounting system of the enterprise and the warehouse management program were integrated, the workflow was automated, and only after that the transport was added to a single information field. Now, to automate the «last mile», it is necessary to make the driver a full participant in the digital logistics system.

8. The digitalization strategy can only be implemented by highly qualified personnel. All participants in the logistics chains must be flexible, quickly react to the changes and make decisions quickly. For this purpose, the specialists must constantly develop their competencies and carry out continuous training [3].

In search of reserves for optimizing activities at individual enterprises, the organization and technology of stream processes are being improved. However, this contributes, as a rule, only to the temporary improvement in the individual indicators of the enterprises 
functioning. The intention to the new management solutions is focused on the integration of the purchase functions, production, transportation, stock management, information and financial flows, and the logistics management is used as an applied strategy [4]. In logistics, the integration is the coordination of such activities as the formation of the logistics infrastructure; information exchange; transportation; lock management; warehousing, cargo handling and packaging. Only brought together into a single system, these functional areas are able to meet the needs of the logistics [5]. This has been reflected in the researches of the scientists. The issues of the integration logistic approaches in management and engineering processes are being examined by Russian and foreign scientists: L.B. Mirotin, E.V. Pustynnikova, V. N. Klochkov, S. A. Gusev, M. A. Betilgiriev, A.E. Brom, E.V. Sudov, A.I. Levin, A.N. Davydov, V.V. Barabanov, E.V. Sudov, A.A. Bochkarev, D. Bowersox, D. Kloss, D. Roy, W. Shapiro, J. M. Williams, A. Klose.

The issues of information flow management in logistics, during the movement of material and other flows, were studied by scientists: A.U. Albekov, B.A. Anikin, N.V. Afanasyeva, G.L. Bagiev, A.M. Gadzhinskiy, E.A. Golikov, M.P. Gordon, V.V. Dybskaya, M.E. Zalmanova, A.V. Zyryanov, O.N. Larin, N.A. Nagapetyants, Yu.M. Nerush, D.T. Novikov, O.A. Novikov, O.D. Protsenko, V.M. Purlik, V.I. Sergeev, V.G. Sankov, A.I. Semenenko, A.A. Smekhov, S.A. Uvarov, V.V. Shcherbakov, D.D. Bowersox, R.H. Ballou, D.D. Cross, W. McMillan, J. Monden [6-9]. However, in our opinion, there is insufficient knowledge of the digitalization issues as one of the directions of the sustainable development of the integrated logistics system of the enterprise.

\section{Methods}

The sustainable development of the integrated logistics system is impossible without an improved information flow. The development of information systems, the introduction of digital technologies into production processes contributed to the digitalization of the economy. These issues were considered in detail in the research works of the authors [10$12]$.

The concept of the digital transformation refers to the introduction of new technologies in all areas of the company to improve its efficiency. During the integration into a single system, the following functionality is combined: purchase, production processes, distribution, stocks, refund (not always allocated as a separate function), as well as information support for any process. With all this in mind, information logistics serves as a connecting link between all the participants in the integrated logistics system. The deployable system should ensure the integration with the existing information logistics systems. At the same time they should provide the coordinated interaction at all stages of the movement of the material flow, taking into account the factors that affect the construction of the logistics system. Taking into account the definition of the integrated logistics, it is legitimate to say that the process of managing all flows in the supply chains is implemented on the basis of the received information. The digitalization contributes to the sustainability of the integrated logistics systems with functional and organizational approaches in the supply chains.

The digitalization of the integrated logistics systems is represented by six characteristic components: partnership, connectivity, adaptability, integration, autonomous control and cognitive improvement. Each of the components performs its specific function.

A partnership is a system of interconnected organizations, united in a single information field. The partnership in this case implies inter-organizational exchange of information and the integration of the information systems data, architectural solutions for the construction of the logistics systems. Thus, the information services and solutions providers combine several partners in strategic information alliances. For example, the union of warehouse and 
transport partners. At the same time, it becomes possible the integration and standardization at all levels of management of data processing and the efficiency of information technologies.

Connectivity is the ability of the information resource to act as a connecting link with other interfaces of partners participating in the logistics system.

Adaptability is the possibility of all system components to change.

Integration is the ability of the system to connect and exchange any data, devices and processes in real time. In the information technologies, the integration of the logistics systems is the process of physical or functional connection of different computing (information) systems and software applications to act as coordinated, holistic logistics flows. Three types of the integration are possible: the horizontal integration, vertical integration, and end-to-end digital integration of logistics along the entire cost chain.

Autonomous management provides decentralized and autonomous decision making in accordance with the logic embedded in the system. The independence literally means acting independently and without any external control.

Cognitive improvement - logistics functions are undergoing fundamental changes with the development of technologies such as artificial intelligence, robots, drones to handle domestic and international movements of goods, so new technologies are constantly being introduced.

A company's digital transformation (digitalization) strategies must take into account the specific situation of each company, including the challenges it faces, the opportunities in its sector, and its goals. Figure 1 shows the interaction between the functionalities of the integrated logistics system, which is examined in detail in [13] and the characteristic components of the digitalization.

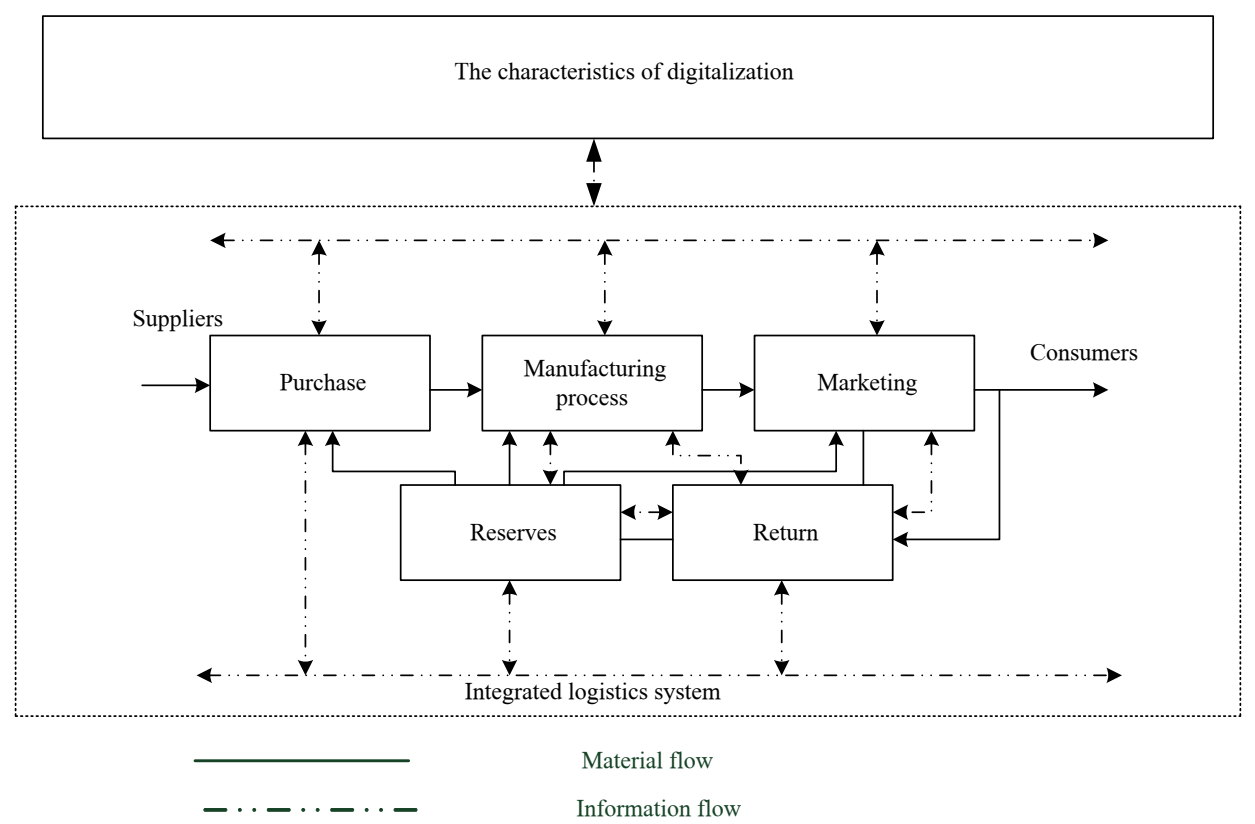

Fig. 1. Digitalization of the integrated logistics systems with the characteristic components.

The integrated logistics system includes many subsystems that need to be combined into a single digital (information) field. Based on the purpose of the research - the choice and substantiation of digital economy methods during building information systems of the 
integrated logistics, an algorithm for its step-by-step solution has been proposed. It has been examined in detail in [10].

As you know, the methodological basis for building the integrated logistics system is a systematic approach that allows you to see the object under study (integrated logistics system) as a complex of interrelated subsystems (functionals), that are united by a common goal, to reveal its integrative properties, internal and external connections.

The variety and diversity of the tasks to be solved with the unity of the final chain of the integrated logistics system, the dispersion of the constituent functionals, the variety of sources of external influences and information flows, that accompany material logistics flows, require the use of such methods of research, design and decision-making that would make it possible to give a comprehensive assessment of the conditions in which this system exists, and determine the options for its rational construction. The chain system must satisfy the certain conditions: integrity and segmentation, connectivity, which determines the integrated qualities of the system, structural ordering, integration, i.e. qualities inherent in the system as a whole: subordination of the chain of the lower level must be subordinated to the goals of a higher level; comparability - at each level of the system there should be subgoals that are related in scale and significance [14]. One of such examples where digital technologies are fully used is the warehouse logistics, which is reflected in the works [1517].

\section{Results and discussion}

The legitimacy of the use of the digital technologies as one of the directions of the sustainable development of the integrated logistics system was confirmed by approbation in the conditions of the companies LLC SVX Logistics and LLC "Fortuna Trans Express". The single level of the information access allows companies to synchronize their work in real time. This makes the supply chain completely transparent. It makes possible to ensure the reliability and availability of information for all participants in the process, reduce personnel costs (logisticians, document flow specialists, storekeepers, warehouse and transport logistics coordinators), simplify paperwork, increase the speed of reaction to market changes. The results of the carried-out work were discussed at the meeting of the working group, where points of view were expressed in favor of this project. It is presented in the section of results and conclusions.

\section{Conclusions}

Modern logistics is impossible without the active digitalization of business process management tools. Moreover, the improvement of logistics operations today is largely determined by the development of infocommunication technologies, network elements and software systems [10-12]. The digitalization contributes not only to the intensification of commercial activities and increased competitiveness, but also to the expansion of the market of the logistics services, a lot of which were provoked by the coronavirus pandemic, the forced transition to new forms and methods of running business. The digitalization also contributes to improving the quality of management activities. The improvement of logistics operations in some cases directly depends on the success in the field of the information technologies. The information flow that is a result of the systems operation is formalized and presented in the form of specific, functionally oriented documents that form a single information space. 


\section{References}

1. N. Semashko, Logistics Appendix, 67, 1 (2020)

2. A. Kochetov, Transport logistics, 5 (2020)

3. V. Kireeva, O. Pirogova, E. Myasnikova, Logistics in retail (2020)

4. V. N. Klochkov, S. A. Gusev, Kant, 1, 67 (2011)

5. Donald J. Bowersox, David J. Kloss, Logistics (2008)

6. E.V. Pustynnikova, Integrated logistics (2017)

7. O. N. Larin, Transport: science, technology, management, 9, 37 (2019)

8. A.I. Semenenko, V.I. Sergeev, Logistics. Foundations of the theory (2001)

9. V. A. Gudkov, L.B. Mirotin, S.A. Shiryaev, D.V. Gudkov, Basics of Logistics (2004)

10. Z. Khmelnitskaya, E. Bogdanova, M. Ivich, Construction of logistics information systems using the digital economy method on the blockchain. Published in Proceedings of the International Scientific and Practical Conference on the Digital Economy (ISCDE) November 07 (2019)

11. Z. Khmelnitskaya, E. Bogdanova, Using digital economy methods in building integrated logistics systems 3rd International Scientific Conference "New Industrialization and Digitalization" December 12 (2020)

12. Z.B. Khmelnitskaya, E.S. Bogdanova, M.L. Ivich, Scientific works of the Free Economic Society of Russia, 227, 360 (2021)

13. E.S. Bogdanova, Integrated Logistics System of Enterprises All-Russian National Scientific and Practical Conference Socio-economic aspects of management in the era of digital technologies development, May 30 (2020)

14. Z.B. Khmelnitskaya, I.N. Tkachenko, Yu. V. Nikiforova, The system of instrument supply for enterprises in the conditions of competitive markets (2009)

15. T.A. Ilyina, D.N. Kirina, SPbSPU Scientific and Technical Bulletin. Economic sciences., 13(4), 36 (2020)

16. D.A. Aksenov, A.P. Kuprikov, P.A. Sahakyan, Bulletin of St. Petersburg State Polytechnic University. Economics, 11-1, 30 (2018)

17. H. Fneng, X. Wang, Y. Duan, Cleaner Production Journal, 260, 121031 (2020) 